\title{
Enacted Stigma, Mental Health, and Protective Factors Among Transgender Youth in Canada
}

\author{
Jaimie F. Veale, ${ }^{1, *}$ Tracey Peter, $^{2}$ Robb Travers, ${ }^{3}$ and Elizabeth M. Saewyc ${ }^{4}$
}

\begin{abstract}
Purpose: We aimed to assess the Minority Stress Model which proposes that the stress of experiencing stigma leads to adverse mental health outcomes, but social supports (e.g., school and family connectedness) will reduce this negative effect.

Methods: We measured stigma-related experiences, social supports, and mental health (self-injury, suicide, depression, and anxiety) among a sample of 923 Canadian transgender 14- to 25-year-old adolescents and young adults using a bilingual online survey. Logistic regression models were conducted to analyze the relationship between these risk and protective factors and dichotomous mental health outcomes among two separate age groups, 14- to 18-year-old and 19- to 25-year-old participants.

Results: Experiences of discrimination, harassment, and violence (enacted stigma) were positively related to mental health problems and social support was negatively associated with mental health problems in all models among both age groups. Among 14-18 year olds, we examined school connectedness, family connectedness, and perception of friends caring separately, and family connectedness was always the strongest protective predictor in multivariate models. In all the mental health outcomes we examined, transgender youth reporting low levels of enacted stigma experiences and high levels of protective factors tended to report favorable mental health outcomes. Conversely, the majority of participants reporting high levels of enacted stigma and low levels of protective factors reported adverse mental health outcomes.

Conclusion: While these findings are limited by nonprobability sampling procedures and potential additional unmeasured risk and protective factors, the results provide positive evidence for the Minority Stress Model in this population and affirm the need for policies and programs to support schools and families to support transgender youth.
\end{abstract}

Keywords: adolescence; minority stress; mental health; stigma; family support; school support

\section{Background}

Transgender youth (sometimes called trans and gender nonconforming) are those whose gender does not match their sex assigned at birth. ${ }^{1}$ An increasing number of transgender people disclose about being transgender during adolescence and early adulthood. ${ }^{2}$ Being perceived as transgender may make youth vulnerable to minority stress, which has been proposed as an explanation for the high rates of mental health difficulties reported among this group. ${ }^{3-5}$
Minority stress theory suggests that members of minority groups experience stressors related specifically to their membership with that group. ${ }^{6}$ These stressors are a result of sociocultural sanctions of status, prejudice, and discrimination, and the theory proposes that they negatively impact psychological wellbeing and adaptation. Experiences of minority stress not only result from specific negative events but also from the overarching experiences in society that the minority individual negotiates in their everyday lives. ${ }^{7}$

\footnotetext{
${ }^{1}$ School of Psychology, University of Waikato, Hamilton, New Zealand.

${ }^{2}$ Department of Sociology, University of Manitoba, Winnipeg, Canada.

${ }^{3}$ Department of Health Sciences, Wilfrid Laurier University, Waterloo, Canada.

${ }^{4}$ Stigma and Resilience Among Vulnerable Youth Centre, School of Nursing, University of British Columbia, Vancouver, Canada.
}

*Address correspondence to: Jaimie F. Veale, PhD, School of Psychology, University of Waikato, Private Bag 3105, Hamilton 3240, New Zealand, E-mail: jveale@ waikato.ac.nz

(c) Jaimie F. Veale et al. 2017; Published by Mary Ann Liebert, Inc. This is an Open Access article distributed under the terms of the Creative Commons Attribution License, which permits unrestricted use, distribution, and reproduction in any medium, provided the original work is properly cited. 
Minority stress theory has been applied to transgender people. ${ }^{8}$ Stressors that are specific to transgender individuals, which have been identified, include feeling or being unsafe in public restrooms, lack of access to legal documents or medical care due to differing records of sex and legal name, and nonaffirmation of one's gender by others. ${ }^{9}$ A number of recent studies have examined components of the minority stress model among transgender samples.

There is now a significant body of evidence for minority stress experiences among transgender youth, with around $80 \%$ reporting verbal harassment ${ }^{10-12}$ or bullying at school. ${ }^{13}$ A study of 290 high school students across the United States found that the majority had been physically harassed in the past year due to their gender expression, almost two-thirds reporting they feel unsafe at school due to their gender expression and more than a quarter reported being physically assaulted in the past year due to their gender expression. ${ }^{10}$ Another study of transgender youth in Virginia found 45\% had reported in-school victimization based on their gender and those who had endured these experiences had a fourfold greater likelihood of suicidal ideation. ${ }^{3}$ Similarly, Ybarra et al. ${ }^{5}$ found that transgender youth who had experienced intense bullying were almost five times more likely to report suicidal ideation, and another study found that transgender youth who had experienced parental abuse were more likely to have attempted suicide. ${ }^{14}$ These findings also mirror studies of transgender adults. ${ }^{9}$

Resilience and protective factors that may reduce minority stress and negative health effects are essential components of the minority stress theory, but this topic has received less attention than stigma and risk factors in empirical research on the theory. ${ }^{15}$ A study of transgender youth in a Los Angeles clinic found that parental support was associated with decreased depressive symptoms and improved life satisfaction. ${ }^{16}$ Studies of transgender adults have also found that family support is associated with better mental health. ${ }^{17}$ School environment is also important for youth, and studies have shown that lesbian, gay, bisexual, transgender, and queer (LGBTQ) youth who report more positive and supportive school experiences are more likely to also report better mental health. ${ }^{18,19}$ Further research is needed to examine the impact of both these stressors and protective factors specifically in estimating the probability of adverse mental health outcomes for transgender youth.

The purpose of this study was to examine the impact of these stressors and protective factors on the mental health of transgender adolescents and young adults (youth). We hypothesize that in accordance with the minority stress model, enacted stigma experiences increase the odds of poor mental health and protective factors, such as school connectedness, family connectedness, and social support, will reduce the odds of these outcomes.

\section{Materials and Methods}

A network of co-investigators and transgender youth advisory councils was set up across Canada to assist with designing and conducting the Canadian Trans Youth Health Survey. Participants completed the survey online in either English or French. They were informed that participation was voluntary and the survey was anonymous. The overall survey included a variety of questions related to physical and emotional health, health and risk exposures, factors that may influence health, sociodemographic information, and gender identity questions to study the measurement of gender identity, and it took the majority of participants less than $60 \mathrm{~min}$ to complete.

\section{Participants}

The Canadian Trans Youth Health Survey was open to participants who were aged 14 to 25, lived in Canada, and identified as trans, genderqueer, or felt their gender did not match their body. The survey had a convenience sample, with participants obtained from promotion of the survey through the study investigators' networks, online advertisements and announcements through e-mail, Twitter, Facebook, and other social media sites, and by the study's researchers contacting Canadian LGBTQ and transgender community organizations to ask them to promote the survey.

There were 1116 responses to the survey, but 50 were outside the age range, 2 had a non-Canadian IP address and did not say they were living in Canada (i.e., they did not report a province or postal code), and a further 116 did not respond beyond the survey's first four demographic questions (age, length of time living in Canada, province, and ethnicity), so all these responses were excluded, leaving 948 responses. Duplicate responses were also identified as responses with the same IP address answering equivalent on demographic questions, and in these cases, the response that was least complete was removed. Generally, it seemed that participants had started the survey, stopped, and then restarted it later. After removing 25 duplicate responses, 923 participants remained. Responses were also screened manually for careless responding by examining participants with the fastest response times, and no evidence of careless responding was observed. 
Younger (14-18 year old) participants were given some different questions for some topics in this study than older (19-25 year old) participants (detailed below). There were fewer $(n=323) 14$ - to 18-year-old participants than 19- to 25-year-old participants $(n=600)$. Details of participants' gender, province of residence, race/ethnicity, amount of time spent living in Canada, and language usually spoken at home are given in Table 1. See also (masked for review) for more details of the sample demographics.

\section{Questionnaire}

The survey was available online from October 2013 until May 2014. All questions were presented in either French or English. Younger transgender youth (14-18 year olds) and older transgender youth (19-25 year olds) were given different versions of the questionnaire to ensure the questions had been validated as appropriate for Canadians of each of these age groups and because school-based surveys measured protective factors specific to that age group: school and family connectedness. Younger youth (323 participants, $35 \%$ of the sample) received questions drawn from school-based population surveys-the British Columbia Adolescent Health Survey, the Manitoba Youth Health Survey, the Ontario Student Drug Use and Health Survey, and the National Youth Smoking Survey. Older youth (600 participants, $65 \%$ of the sample) received questions drawn from national telephone-based population surveys that include this age group-the
Canadian Community Health Survey and the General Social Survey. Questions addressed the same topics, but the wording of the questions was often different because the two versions of questionnaire were drawn from different sources. Using questions drawn from Canadian population-based surveys ensured that questions are widely used and had undergone thorough validation. Recruitment methods did not differ between these two age groups and these two age groups had the same overall pattern of demographics.

Enacted stigma. Following the lead of other studies, ${ }^{20}$ an Enacted Stigma Index was created based on reports of experiencing of a wide range of violent or discriminatory behaviors, including discrimination, verbal harassment, cyberbullying, school bullying, physical abuse, sexual harassment, sexual abuse, and sexual exploitation. The questions, outlined in Table 2, had either yes or no response options or asked participants to report the frequency of these experiences. In the latter cases, responses were dichotomized into "yes" or "no" if participants had experienced that type of violence, and the index was calculated as a summed score of the number of these different experiences. Because 14-18 and 19-25 year olds were given some different questions on these topics, Enacted Stigma Indices differed between these two age groups.

Mental health. All participants responded to a question on nonsuicidal self-injury (NSSI) asking participants if they "had hurt or injured themselves on purpose without

Table 1. Demographics of the Sample Delineated by Age Group

\begin{tabular}{|c|c|c|c|c|c|c|c|c|c|c|c|}
\hline Gender & $\begin{array}{c}14-18 \\
n(\%)\end{array}$ & $\begin{array}{c}19-25 \\
n(\%)\end{array}$ & Province & $\begin{array}{c}14-18 \\
n(\%)\end{array}$ & $\begin{array}{l}19-25 \\
n(\%)\end{array}$ & Race/ethnicity ${ }^{a}$ & $\begin{array}{c}14-18 \\
n(\%)\end{array}$ & $\begin{array}{c}19-25 \\
n(\%)\end{array}$ & $\begin{array}{l}\text { Time living } \\
\text { in Canada }\end{array}$ & $\begin{array}{c}14-18 \\
n(\%)\end{array}$ & $\begin{array}{c}19-25 \\
n(\%)\end{array}$ \\
\hline Boys/men & $140(47)$ & $216(36)$ & Alberta & $41(13)$ & $73(12)$ & White only & $225(72)$ & $446(75)$ & Less than 1 year & $1(0)$ & $6(1)$ \\
\hline Girls/women & $32(11)$ & $107(20)$ & British Columbia & $85(26)$ & $124(21)$ & Aboriginal & 42 (13) & $51(9)$ & 1 to 2 years & $2(1)$ & $6(1)$ \\
\hline $\begin{array}{c}\text { Nonbinary } \\
\text { (AFAB) }\end{array}$ & $110(37)$ & $173(32)$ & Manitoba & $13(4)$ & $19(3)$ & Black & $6(2)$ & $9(2)$ & 3 to 5 years & $5(2)$ & $15(3)$ \\
\hline \multirow[t]{8}{*}{$\begin{array}{c}\text { Nonbinary } \\
\text { (AMAB) }\end{array}$} & $18(6)$ & $43(8)$ & New Brunswick & $14(4)$ & $9(2)$ & $\begin{array}{c}\text { Central/South } \\
\text { American }\end{array}$ & $8(3)$ & $4(1)$ & 6 years or more & $31(10)$ & $54(9)$ \\
\hline & & & Newfoundland & $11(3)$ & $21(4)$ & $\begin{array}{l}\text { West Asian } \\
\text { or Arab }\end{array}$ & $2(1)$ & $14(2)$ & Entire life & $282(88)$ & $516(86)$ \\
\hline & & & $\begin{array}{l}\text { Northwest } \\
\text { Territories }\end{array}$ & $1(0)$ & $3(1)$ & Southeast Asian & $3(1)$ & $10(2)$ & Usual language & & \\
\hline & & & Nova Scotia & $20(6.2)$ & $43(7)$ & South Asian & $4(1)$ & $8(1)$ & English only & $252(79)$ & $442(74)$ \\
\hline & & & Ontario & $87(27)$ & $181(30)$ & East Asian & $14(5)$ & $28(5)$ & French only & $12(4)$ & $47(8)$ \\
\hline & & & $\begin{array}{l}\text { Prince Edward } \\
\text { Island }\end{array}$ & $1(0)$ & $3(1)$ & Multi-racial & $9(3)$ & $20(3)$ & $\begin{array}{l}\text { English and } \\
\text { French }\end{array}$ & $24(8)$ & $42(7)$ \\
\hline & & & Quebec & $31(10)$ & $106(18)$ & Other & & & $\begin{array}{c}\text { English and } \\
\text { another } \\
\text { language }\end{array}$ & $19(6)$ & $41(7)$ \\
\hline & & & Saskatchewan & $17(5)$ & $18(3)$ & & & & Other & $11(3)$ & $22(4)$ \\
\hline
\end{tabular}

ns differ due to missingness.

aparticipants could choose more than one race/ethnicity. Those who responded as white and one other race/ethnicity are listed in this study as other race/ethnicity. Those who responded as more than one non-white ethnicity are listed as multiracial.

$A F A B$, assigned female at birth; $A M A B$, assigned male at birth. 
Table 2. Prevalence of Enacted Stigma Experiences

\begin{tabular}{|c|c|c|c|}
\hline \multirow{2}{*}{$\begin{array}{l}\text { 14-18 year olds } \\
\text { Number of reasons for experiencing discrimination in the past year }\end{array}$} & \multicolumn{3}{|c|}{ 19-25 year olds } \\
\hline & $\begin{array}{l}\text { Median }=3 \\
M=2.94 \\
\mathrm{SD}=2.47\end{array}$ & $\begin{array}{l}\text { Number of reasons for experiencing } \\
\text { discrimination in the past } 5 \text { years }\end{array}$ & $\begin{array}{l}\text { Median }=4 \\
M=3.48 \\
\mathrm{SD}=2.21\end{array}$ \\
\hline $\begin{array}{l}\text { Harassment in the past year for } \\
\text { Race or culture } \\
\text { Sexual orientation } \\
\text { Body size/shape/appearance } \\
\text { Gender identity }\end{array}$ & $\begin{array}{r}n(\%) \\
32(17) \\
120(63) \\
106(55) \\
132(69)\end{array}$ & & $n(\%)$ \\
\hline Cyberbullying & & Cyberbullying & \\
\hline Felt unsafe with internet contact & $56(29)$ & Received threatening messages & $155(45)$ \\
\hline Been bullied on the internet & $64(33)$ & $\begin{array}{l}\text { Received hateful comments } \\
\text { Had threatening e-mails sent out } \\
\text { Using their identity } \\
\text { Other cyberbullying }\end{array}$ & $\begin{array}{c}141(42) \\
18(5) \\
106(33)\end{array}$ \\
\hline \multicolumn{4}{|l|}{ Bullying in the past year } \\
\hline $\begin{array}{l}\text { Been bullied/taunted/ridiculed } \\
\text { Been bullied at school }\end{array}$ & $\begin{array}{l}122(64) \\
100(52)\end{array}$ & $\begin{array}{l}\text { Physical abuse by someone close } \\
\text { as a child/teenager }\end{array}$ & $123(33)$ \\
\hline Not attended school due to feeling unsafe in past 30 days & $60(26)$ & $\begin{array}{l}\text { Physical attack to self or family } \\
\text { member in the past year }\end{array}$ & $37(11)$ \\
\hline Physically threatened/injured past year & $69(36)$ & Contact/use of violence services & $178(52)$ \\
\hline Threatened with weapon past year & $18(9)$ & in the past 5 years & \\
\hline Physically hurt by someone in family past year & $29(15)$ & & \\
\hline Sexual abuse & $74(35)$ & Forced/attempted unwanted & $27(7)$ \\
\hline Sexual touch by older or stronger family member & $20(10)$ & sexual activity in the past year & \\
\hline Unwanted sexual touch by any adult or person outside family & $50(24)$ & $\begin{array}{l}\text { Forced unwanted sexual activity by } \\
\text { current partner past } 5 \text { years }\end{array}$ & $15(4)$ \\
\hline Physically hurt or forced sex by a date & $37(24)$ & Physically hurt or forced sex by a date & $92(28)$ \\
\hline Physically forced into sexual intercourse & $49(21)$ & Physically forced sexual intercourse & $103(25)$ \\
\hline \multicolumn{4}{|l|}{ Sexual harassment past year: } \\
\hline Unwanted sexual comments & $137(71)$ & Unwanted sexual touch in the past year & $115(33)$ \\
\hline Unwanted sexual touch & $72(37)$ & & \\
\hline Engaged in sexual activity for money, food, shelter, drugs/alcohol & $15(6)$ & & \\
\hline
\end{tabular}

Questions asked if participants had ever experienced these events unless other timeframe noted.

wanting to die? (For example, by cutting, burning, or bruising yourself on purpose)." In addition to British Columbia, youth health surveys in Massachusetts, Minnesota, and Ontario have used this question.

Younger (14-18 year old) participants were asked "During the past 12 months, how many times did you actually attempt suicide?" Older (19-25 year old) participants were asked if they had ever seriously considered suicide or taking their own life. While we also collected data on suicidal attempts for 19-25 year olds, we decided to not use it in this study because it was reduced due to an error we made in our survey skip logic.

Younger participants were also asked single questions measuring stress and despair taken from the General Well-being Schedule ${ }^{21}$ : "during the past 30 days, have you felt you were under any strain, stress, or pressure?" and "during the past 30 days, have you felt so discouraged or hopeless, or had so many problems you wondered if anything was worthwhile?" Response options ranged from "not at all" to "extremely so, to the point I couldn't do my work or deal with things." After consultation with adolescent medicine specialists as to clinically relevant levels of stress and despair, responses were dichotomized into those reporting extreme stress and extreme despair versus all other responses, ${ }^{20}$ to allow a consistent type of analysis (binary logistic regression illustrating predictive probabilities) for all the analyses in this study.

The first question of the World Health Organization Composite International Diagnostic Interview Short Form was used to measure depression among 19-25 year olds. This was a yes/no question asking, "During the past 12 months, was there ever a time when you felt sad, blue, or depressed for 2 weeks or more in a row?"22

\section{Protective factors.}

School connectedness. The 5-item School Connectedness Scale ${ }^{23}$ measures feelings of belonging, engagement, and connection to one's school (e.g., "I feel I am part of my school") with 4-point response options from "strongly disagree" to "strongly agree." One study reported that this scale has adequate concurrent validity, reliability, and measurement stability across 18 ethnic groups. ${ }^{24}$ This scale was given to $14-18$ year olds. 
Family connectedness. This construct was measured among 14-18 year olds by seven items based on those used in the British Columbia Adolescent Health Survey, the Minnesota Student Survey, and other sources to assess family connectedness (e.g., "how much do you feel that your family cares about your feelings?"), along with an item asking the extent to which parents care, and an item asking the extent to which other adults care. $^{25}$ Items had 5-point response options from "not at all" to "very much." One study found high levels of internal consistency reliability for the first five items of this scale. ${ }^{25}$

Older (19-25 year-old) participants were given an 8item Parent Connectedness Scale. ${ }^{26}$ This scale has four items assessing closeness and perceptions of caring from mother or father (or the people they considered to be in these roles) on 5-point response scales from "not at all" to "very much," and perceived warmth and satisfaction with these relationships (e.g., "Most of the time, my father (or the person I consider my father) is warm and loving toward me") on 5-point response scales from "strongly disagree" to "strongly agree."

Friend support. Among 14-18 year olds, perception of friends caring was measured using a single item, "how much do you feel that your friends care about you?" using a 5-point response scale from "not at all" to "very much." 26

Social support. Among 19-25 year olds, more generalized social support was assessed using the 12-item version of the Medical Outcomes Study Social Support Survey. ${ }^{27}$ This scale measured the availability of people for tangible, affectionate, positive interaction, and emotional-information social support on 5-point response scales from "none of the time" to "all of the time." This version of the scale performed well on confirmatory factor analysis as either a single factor or a higherorder factor model, and it had excellent reliability. ${ }^{27}$

\section{Data analysis}

All analyses were conducted using SPSS version 22. Missing values on scales were imputed using SPSS's expectation maximization method, in which values were estimated from maximum likelihood-based regression equations based on other responses in the scale. Numbers of participants varied across the analyses because of missing data, usually due to participant attrition before completing the entire survey. This meant that items that were given to participants later in the survey had fewer responses. We had no reason to believe that the missing values differed across different levels of mental health, enacted stigma, or protective factors (i.e., we believe data were missing at random); so we did not attempt to correct for this missingness.

Probability profiling ${ }^{20,28}$ was used to illustrate the results of logistic regression models. As per the original procedure, scales were all converted to range from 0 to 1 , so that their effects could be compared. ${ }^{28}$ Bivariate models of each of the risk and protective factors predicting mental health outcomes were conducted first and multivariate models were selected based on including the Enacted Stigma Index as the only risk factor and using effect size for the protective factors. Only those protective factors that had odds ratios of less than 0.5 in the multivariate models (in other words, the bivariate model needed to predict that those scoring highest on the protective factor had half the odds of the negative mental health outcome as those scoring lowest) were included in the multivariate models. Age was also included as a predictor in the multivariate models. Predicted probabilities for various combinations of high (90th percentile) or low (10th percentile) levels of risk and protective factors were then calculated based on the logistic regression equations.

\section{Results}

Prevalence of discrimination, harassment, and violence experiences used to create the Enacted Stigma Indices are given in Table 2 . These results show widely varying prevalence of reported experiences. While some violence experiences were reported by a notable minority, a number of these enacted stigma experiences were reported by the majority of Canadian transgender youth. Descriptive statistics and reliability coefficients for the protective factors are given in Table 3.

Younger youth (14-18 year olds)

Table 4 outlines the prevalence of mental health outcomes and results from logistic regression models for

Table 3. Descriptive Statistics and Reliability Coefficients for Protective Factors Used in This Study

\begin{tabular}{|c|c|c|c|c|c|}
\hline Protective factor & $\begin{array}{l}\text { Age } \\
\text { group }\end{array}$ & $n$ & Mean & $\begin{array}{l}\text { Standard } \\
\text { deviation }\end{array}$ & $\begin{array}{c}\text { Cronbach's } \\
\alpha\end{array}$ \\
\hline $\begin{array}{l}\text { Family connectedness } \\
\text { scale }\end{array}$ & $14-18$ & 260 & 0.46 & 0.26 & 0.92 \\
\hline $\begin{array}{l}\text { School connectedness } \\
\text { scale }\end{array}$ & $14-18$ & 210 & 0.49 & 0.26 & 0.87 \\
\hline $\begin{array}{l}\text { Perception of friends } \\
\text { caring }\end{array}$ & $14-18$ & 232 & 0.63 & 0.31 & - \\
\hline Parent connectedness & $19-25$ & 427 & 0.64 & 0.23 & 0.96 \\
\hline Social support & $19-25$ & 476 & 0.60 & 0.24 & 0.94 \\
\hline
\end{tabular}


Table 4. Prevalence of Mental Health Outcomes and Results of Bivariate and Multivariate Logistic Regression Models Among Younger Youth (14-18 Year Olds)

\begin{tabular}{|c|c|c|}
\hline & $\begin{array}{l}\text { Bivariate } \\
\text { models }^{\mathrm{a}}\end{array}$ & $\begin{array}{l}\text { Multivariate } \\
\text { models }^{\mathbf{b}}\end{array}$ \\
\hline & & \\
\hline $\begin{array}{l}\text { ISSI in the past year } \\
\text { Enacted Stigma Index } \\
\text { Family Connectedness Scale } \\
\text { Age } \\
\text { School Connectedness Scale } \\
\text { Perception of friends caring }\end{array}$ & $\begin{array}{r}1.26^{* *}(1.16,1.38) \\
0.03^{* *}(0.01,0.15) \\
\text { - }^{c} \\
0.28(0.07,1.06) \\
0.32(0.10,1.03)\end{array}$ & $\begin{aligned} \text { Yes }=147 ; \mathrm{Nc} \\
1.25^{* *}(1.13, \\
0.10^{*}(0.02, \\
0.67^{*}(0.47, \\
{ }_{\mathrm{d}}{ }^{\mathrm{d}}\end{aligned}$ \\
\hline $\begin{array}{l}\text { uicide attempt past year } \\
\text { Enacted Stigma Index } \\
\text { Family Connectedness Scale } \\
\text { Perception of friends caring } \\
\text { Age } \\
\text { School Connectedness Scale }\end{array}$ & $\begin{array}{c}1.10^{* *}(1.05,1.16) \\
0.05^{* *}(0.01,0.18) \\
0.13^{* *}(0.05,0.37) \\
0.08^{* *}(0.02,0.31)\end{array}$ & $\begin{array}{r}\text { Yes }=68 ; \mathrm{No}=12 \\
1.09^{* *}(1.03,1.1 \\
0.23(0.05,1.1 \\
0.25^{*}(0.07,0.8 \\
0.76 \underset{\text { (0.56 }}{(0.5 .0}\end{array}$ \\
\hline $\begin{array}{l}\text { xtreme stress past month } \\
\text { Enacted Stigma Index } \\
\text { School Connectedness Scale } \\
\text { Age } \\
\text { Family Connectedness Scale } \\
\text { Perception of friends caring }\end{array}$ & $\begin{array}{r}1.10^{* *}(1.05,1.15) \\
0.07^{* *}(0.02,0.24) \\
-^{c} \\
0.11^{* *}(0.03,0.35) \\
0.33^{*}(0.13,0.84)\end{array}$ & $\begin{array}{c}\text { Yes }=85 ; \mathrm{No}=104 \\
1.07^{* *}(1.02,1.13) \\
0.10^{* *}(0.03,0.38) \\
0.86(0.65,1.14) \\
\text { _ }^{\mathrm{d}}\end{array}$ \\
\hline $\begin{array}{l}\text { Extreme despair past month } \\
\text { Enacted Stigma Index } \\
\text { Family Connectedness Scale } \\
\text { School Connectedness Scale } \\
\text { Age } \\
\text { Perception of friends caring }\end{array}$ & $\begin{array}{c}1.11^{* *}(1.05,1.17) \\
0.03^{* *}(0.01,0.12) \\
0.04^{* *}(0.01,0.16) \\
{ }^{c} \\
0.22^{* *}(0.08,0.62)\end{array}$ & $\begin{array}{r}\text { Yes }=53 ; \mathrm{No}=136 \\
1.06(1.00,1.13) \\
0.11^{*}(0.02,0.68) \\
0.15^{*}(0.03,0.81) \\
0.99(0.72,1.37) \\
\text { _ }^{-}\end{array}$ \\
\hline
\end{tabular}

${ }^{\text {a }}$ Results of separate models with a single risk/protective factor predictor (i.e., four separate models for each mental health outcome).

${ }^{b}$ Single model including all predictors for each mental health outcome.

${ }^{\mathrm{C}}$ Bivariate models of age predicting mental health outcomes were not assessed.

${ }^{\mathrm{d}}$ Not included in the multivariate model due to odds ratio $>0.5$.

${ }^{*} p<0.05 ;{ }^{* *} p<0.01$.

NSSI, nonsuicidal self-injury.

younger participants (14-18 year olds). Mental health problems were highly prevalent among the sample, with almost three-quarters reporting NSSI in the past year, over one-third having attempted suicide in the past year, and $45 \%$ and $28 \%$ reporting extreme stress and despair in the past 30 days, respectively. Odds ratios for predictor variables of bivariate logistic regression analyses (with single risk or protective factors) and final multivariate logistic regression analyses (with multiple risk and protective factors) are also given in Table 4. The Enacted Stigma Index was a positive predictor of mental health problems in all the regression models. It had a particularly strong effect in the NSSI models-for each enacted stigma experience, participants were $25 \%$ more likely to have reported NSSI in the past year. While all the protective factors negatively predicted mental health difficulties, they did not all meet the criterion of a 0.5 odds ratio to be included in the final multivariate models due to these predictors being inter-
Table 5. Probability Profiling Results for Mental Health Outcomes for 14-18 Year Olds

\begin{tabular}{|c|c|c|}
\hline & $\begin{array}{l}\text { High (90th } \\
\text { percentile) } \\
\text { Enacted } \\
\text { Stigma } \\
\text { Index (\%) }\end{array}$ & $\begin{array}{c}\text { Low (10th } \\
\text { percentile) } \\
\text { Enacted } \\
\text { Stigma } \\
\text { Index (\%) }\end{array}$ \\
\hline $\begin{array}{l}\text { High family connectedness } \\
\text { (90th percentile) }\end{array}$ & 60 & 23 \\
\hline $\begin{array}{l}\text { Low family connectedness } \\
\text { (10th percentile) }\end{array}$ & 99 & 91 \\
\hline \multicolumn{3}{|l|}{$\begin{array}{l}\text { Probability of a suicide attempt } \\
\text { in the past year }\end{array}$} \\
\hline High on both protective factors & 25 & 7 \\
\hline $\begin{array}{l}\text { High family connectedness, low } \\
\text { perception of friends caring }\end{array}$ & 48 & 18 \\
\hline $\begin{array}{l}\text { Low family connectedness, high } \\
\text { perception of friends caring }\end{array}$ & 48 & 18 \\
\hline Low on both protective factors & 72 & 38 \\
\hline \multicolumn{3}{|l|}{ Extreme stress past month } \\
\hline High school connectedness & 48 & 15 \\
\hline Low school connectedness & 75 & 37 \\
\hline \multicolumn{3}{|l|}{ Extreme despair past month } \\
\hline High on both protective factors & 10 & 4 \\
\hline $\begin{array}{l}\text { High family connectedness, } \\
\text { low school connectedness }\end{array}$ & 35 & 16 \\
\hline $\begin{array}{l}\text { Low family connectedness, } \\
\text { high school connectedness }\end{array}$ & 31 & 14 \\
\hline Low on both protective factors & 68 & 54 \\
\hline
\end{tabular}

correlated. Family Connectedness was usually the strongest protective factor in the final models, but School Connectedness was a significant protective factor in the models for extreme stress and extreme despair, and perception of friends caring was also predictive of suicide attempts in the past year.

From the multivariate logistic regression analyses, probability profiles were calculated based on combinations of risk and protective factors. These probability profiles for 14-18 year olds are outlined in Table 5, illustrating how the probabilities of these mental health outcomes vary widely with different combinations of reporting high or low levels of risk and protective factors. For example, with having ever seriously considered suicide, the model predicted that a transgender youth who had experienced high levels of discrimination, harassment, or violence perpetrated against them, who were also low on protective factors, had a $72 \%$ probability of reporting this. This estimate is reduced markedly when family connectedness and/or friends caring was high, but even with these supports, the estimated probability remains at close to $50 \%$. Even if transgender youth reported low levels of enacted stigma, when levels of parental and social supports are low, their probability of serious suicidal ideation was still at $38 \%$. The optimal scenario is for transgender youth to have high 


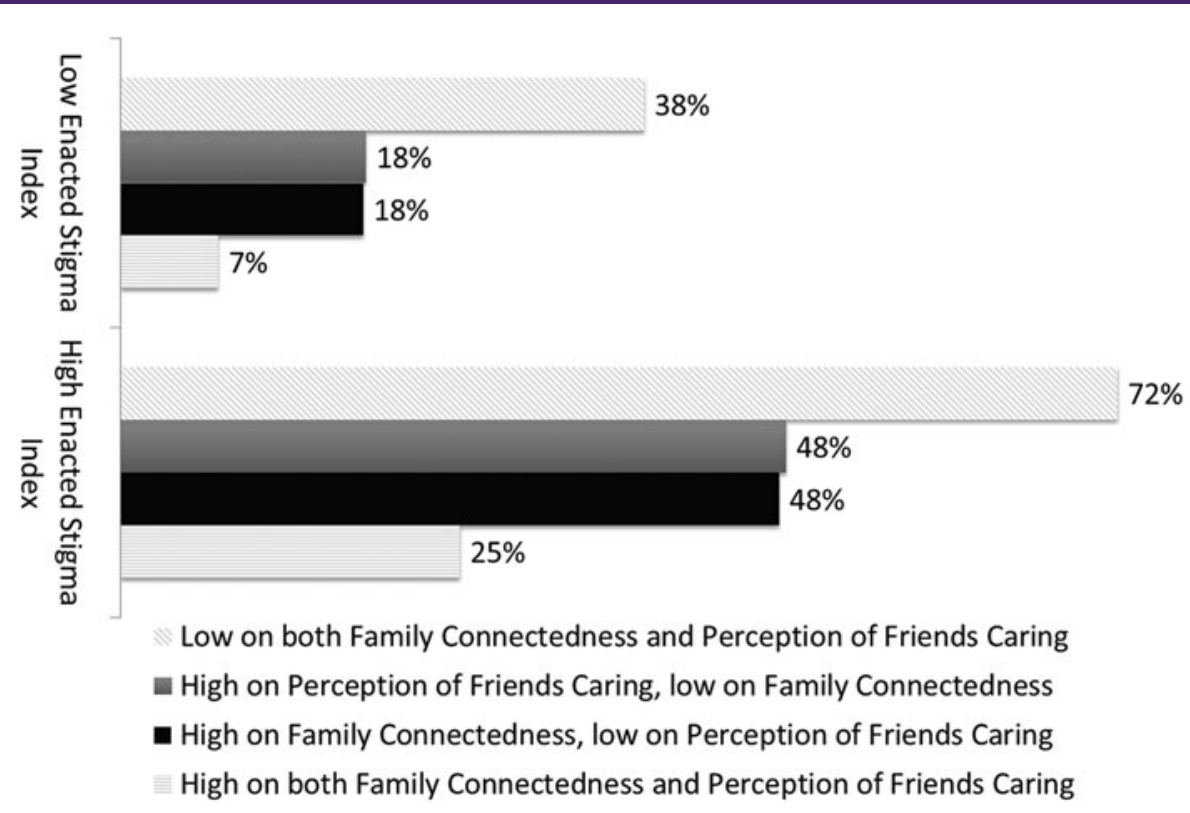

FIG. 1. Probability of having attempted suicide in the past 12 months for 14-18 year olds.

levels of family connectedness and friends caring, and low levels of enacted stigma exposure-in such cases, the probability of suicide attempts dropped to 7\%. Figure 1 also illustrates this example.

\section{Older youth (19-25 year olds)}

Prevalence of mental health outcomes and odds ratios for predictor variables of bivariate and multivariate logistic regression models for 19-25 year olds are given in Table 6. More than half of these participants reported NSSI in the past year, almost three-quarters reported they had ever seriously considered suicide, and $71 \%$ reported having felt sad or depressed for more than 2 weeks in the past year. The Enacted Stigma Index was a positive predictor of mental health problems in all the regression models, and similarly, Social Support was a negative predictor in all the models. Parent connectedness also played a role in the final multivariate model, predicting lower odds of serious suicidal thoughts. Probability profiling results for these mental health outcomes for 19 to 25 year olds are given in Table 7, and as with the 14 to 18 year olds, these show greatly varying probabilities depending on the mix of risk and protective factors.

\section{Discussion}

At first glance, the findings paint a very dark picture for transgender youth in Canada-using a geographically diverse national sample of Canadian transgender youth, we found three out of four reported NSSI behaviors in the past year, nearly half experienced extreme stress in the past 30 days, and a third attempted suicide in the last year. These findings are consistent with

Table 6. Prevalence of Mental Health Outcomes and Results of Bivariate and Multivariate Logistic Regression Models Among Older Youth (19-25 Year Olds)

\begin{tabular}{|c|c|c|}
\hline & $\begin{array}{l}\text { Bivariate } \\
\text { models }^{\mathrm{a}}\end{array}$ & $\begin{array}{l}\text { Multivariate } \\
\text { models }^{\mathrm{b}}\end{array}$ \\
\hline & $\begin{array}{l}\text { Odds ratio } \\
\text { (95\% Cls) }\end{array}$ & $\begin{array}{l}\text { Odds ratio } \\
\text { (95\% Cls) }\end{array}$ \\
\hline $\begin{array}{l}\text { NSSI in the past year } \\
\text { Enacted Stigma Index } \\
\text { Social support } \\
\text { Age } \\
\text { Parent connectedness }\end{array}$ & $\begin{array}{r}1.29^{* *}(1.17,1.41) \\
0.15^{* *}(0.06,0.38) \\
\bar{c}^{c} \\
0.42(0.17,1.02)\end{array}$ & $\begin{array}{c}\text { Yes }=182 ; \mathrm{No}=174 \\
1.27^{* *}(1.16,1.39) \\
0.19^{* *}(0.07,0.51) \\
0.81^{* *}(0.73,0.92) \\
{ }_{\mathrm{d}} \mathrm{d}\end{array}$ \\
\hline $\begin{array}{l}\text { Seriously considered suicide ever } \\
\text { Enacted Stigma Index } \\
\text { Social support } \\
\text { Parent connectedness } \\
\text { Age }\end{array}$ & $\begin{array}{c}1.43^{* *}(1.25,1.64) \\
0.10^{* *}(0.03,0.32) \\
0.11^{* *}(0.03,0.38) \\
{ }_{c}^{c}\end{array}$ & $\begin{array}{r}\text { Yes }=248 ; \mathrm{No}=86 \\
1.28^{* *}(1.20,1.58) \\
0.19^{*}(0.05,0.67) \\
0.38(0.10,1.45) \\
0.87(0.76,1.01)\end{array}$ \\
\hline $\begin{array}{l}\text { Depression past year } \\
\text { Enacted Stigma Index } \\
\text { Social support } \\
\text { Age } \\
\text { Parent connectedness }\end{array}$ & 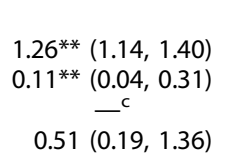 & $\begin{array}{c}\text { Yes }=274 ; \mathrm{No}=113 \\
1.24^{* *}(1.11,1.37) \\
0.14^{* *}(0.05,0.40) \\
0.89 \underset{(0.79,1.00)}{(0 .}\end{array}$ \\
\hline
\end{tabular}

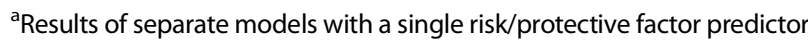
(i.e., four separate models for each mental health outcome).

${ }^{\mathrm{b}}$ Single models including all predictors for each mental health outcome.

'Bivariate models of age predicting mental health outcomes were not assessed.

${ }^{\mathrm{d}}$ Not included in the multivariate model due to odds ratio $>0.5$.

${ }^{*} p<0.05 ;{ }^{* *} p<0.01$. 
Table 7. Probability Profiling Results for Mental Health Outcomes for 19-25 Year Olds

\begin{tabular}{|c|c|c|}
\hline & $\begin{array}{l}\text { High (90th } \\
\text { percentile) } \\
\text { Enacted } \\
\text { Stigma } \\
\text { Index (\%) }\end{array}$ & $\begin{array}{c}\text { Low (10th } \\
\text { percentile) } \\
\text { Enacted } \\
\text { Stigma } \\
\text { Index (\%) }\end{array}$ \\
\hline \multicolumn{3}{|l|}{ NSSI in the past year } \\
\hline High social support (90th percentile) & 48 & 21 \\
\hline Low social support (10th percentile) & 83 & 59 \\
\hline \multicolumn{3}{|l|}{ Seriously considered suicide ever } \\
\hline High on both protective factors & 85 & 36 \\
\hline $\begin{array}{l}\text { High social support, low parent } \\
\text { connectedness }\end{array}$ & 91 & 50 \\
\hline $\begin{array}{l}\text { Low social support, high parent } \\
\text { connectedness }\end{array}$ & 95 & 64 \\
\hline Low on both protective factors & 97 & 77 \\
\hline \multicolumn{3}{|l|}{ Depression past year } \\
\hline High social support & 73 & 44 \\
\hline Low social support & 92 & 78 \\
\hline
\end{tabular}

previous studies of transgender youth, ${ }^{3,5,14,29}$ and further signal the considerable and urgent concerns for transgender youth, their families, and their extended communities. Our results show that these negative mental health outcomes are strongly related to the widespread experiences of stressors. This is consistent with the minority stress model applied to transgender people $^{8}$ and this was the first study to examine the impact of both risk and protective factors in the probability of developing adverse mental health outcomes for transgender people.

While we found that the majority of transgender youth reporting high levels of enacted stigma reported high prevalence of a range of mental health concerns, we also found that supportive environments (i.e., family, friends, and schools) appear to reduce these negative impacts. While supportive family and school environments are important for healthy development of all youth, these results show that these are even more important for transgender youth who face high levels of enacted stigma and minority stress. This study found that when transgender youth have supportive family and school environments, even when they have high exposure to enacted stigma, the stress is buffered to an extent. The importance of protective factors demonstrates that transgender youth have a greatly reduced likelihood of negative mental health outcomes when they reported being strongly connected to their family or their school, even when they experienced stigma and discrimination elsewhere.

While the minority stress theory emphasizes the importance of community resilience, ${ }^{15}$ this study did not examine support received specifically from the transgender community. Nevertheless, our probability profiling results illustrated the strong relationship between mental health and protective factors that we did examine, suggesting that these protective factors are important. Community-level resilience might have been captured indirectly through the school connectedness, family connectedness, and social support variables assessed. For example, transgender community groups and organizations play a crucial role in supporting schools and families to support transgender youth. Our findings also show that primary prevention strategies, which generally involve reducing the circumstances that perpetuate suicidality and selfinjury, should implement programs and/or policies that enhance social support and connectedness and prevent alienation or isolation of transgender youth. These may include specific gender identity antibullying strategies in schools and workplaces.

The results of this study suggest that to reduce the risk of adverse mental health outcomes, schools and educational institutions need to become safer and more affirming places for transgender youth, regardless of whether or not school staff are aware of the identities of transgender youth. To this end, educational systems should work directly with transgender youth, their friends/family and other supports, professionals, and community leaders to develop relevant and effective programs and policies that create supportive and affirming school environments. Supportive school clubs, such as Gay Straight Alliances (GSAs) or more recently Gender and Sexuality Alliances, in schools can help foster a sense of connectedness to the school, while allowing a space for LGBTQ youth to create their own structures and values, and attempt to provide a space that is free of anti-LGBTQ stigma. ${ }^{30}$ GSAs have also been found to have positive effects on all students, not only LGB students, providing evidence for them aiding transgender students as well. ${ }^{31}$ This is important because it also allows access to resilience factors such as social and emotional support from others with a shared identity or experiences. ${ }^{9}$

Meyer also recognized individual-level resilience in coping with minority stress as an additional area for potential intervention for enhancing resilience, but he suggested caution with focusing on this because individuals within different groups have different access to this resilience. ${ }^{15}$ Nevertheless, secondary prevention strategies, which address immediate responses to harm and distress and improve resilience in individuals, may also be needed to address these serious mental health 
concerns. These could include early detection of NSSI, distress, and suicidal behavior, complete with improved access to appropriate health and mental health that is age specific, and not merely transgender friend$l y$, but is transgender affirming. ${ }^{32}$ Since our results suggest that negative mental health outcomes are complex, with several co-occurring risk and protective factors, secondary prevention strategies should also highlight the importance of family, friends, and other supportive people in the lives of transgender youth.

The most noteworthy limitation of this research is with the sampling procedures undertaken. Specifically, the sampling frame was based on nonprobability recruitment methods and, as such, there is no way of knowing how representative the sample is from the larger transgender youth population across Canada. This study had relatively fewer trans girls/women and nonbinary assigned male at birth participants. This may have been a result of the survey's promotion through our networks reaching more trans boys/men and nonbinary assigned female at birth youth, although other recent similar studies of trans youth have also had the same demographic distribution, ${ }^{33,34}$ suggesting the underlying demographic distribution of the population may have also been a factor in this. Given the recruitment techniques, participants who are more resourceful and engaged in the transgender community were likely to have been overrepresented. However, employing traditional probability sampling techniques would be difficult given the small proportion and relatively hidden nature of transgender populations. This study's methodology allowed us to gather a large sample size, giving us added confidence about the generalizability of our findings, even if these generalizations ought to be made with caution.

The questions used in our survey also had limitations. This study relied on single questions with responses dichotomized for mental health outcomes, while these questions are widely used and validated on large probability surveys. While this allowed us to use probability profiling results as a guide to illustrate the amount of impact the risk and protective factors may exert on mental health outcomes for transgender youth, these probability profiling results illustrated only those outcomes at more extreme ends (10th and 90th percentiles). The use of single-item measures is a trade-off that was made so that a broad range of topics could be included in a survey of this length. Another limitation is that the Enacted Stigma Index used in this study included experiences that might be expected due to anti-transgender stigma, but except for one discrim- ination question, it did not include questions specifically about anti-transgender stigma. This study also relied on cross-sectional data when longitudinal data would be preferable to test these causal hypotheses. Finally, other protective factors, such as living in their felt gender and access to competent healthcare, were not included in our estimates, and their inclusion may have resulted in lower estimates of poor mental health for those youth reporting the best-case scenario.

\section{Conclusions}

These results are in accordance with the minority stress theory and suggest that experiences of stigma, and family and social support are very important for the mental health of transgender youth. When youth feel cared about and connected to their families, friends, and schools, the negative impacts of stigma experiences on mental health may be reduced. Like all youth, transgender youth need care and social supports to reach their maximum potential as healthy adults. Given the magnitude of the consequences of enacted stigma coupled with weak or absent protective factors, strategies to reduce stigma and support transgender youth and their families are imperative to prevent negative health outcomes among transgender youth.

\section{Author Disclosure Statement}

This research was supported by grant no. MOP 119472 from the Canadian Institutes of Health Research, Institute of Gender and Health (E.M.S., PI), and by postdoctoral fellowship awards (J.F.V.) from the Canadian Institutes of Health Research and the Michael Smith Foundation for Health Research. No competing financial interests exist.

\section{References}

1. Scheim Al, Bauer GR. Sex and gender diversity among transgender persons in Ontario, Canada: results from a respondent-driven sampling survey. J Sex Res 2015;52:1-14.

2. Olson J, Forbes C, Belzer M. Management of the transgender adolescent. Arch Pediatr Adolesc Med 2011;165:171-176.

3. Goldblum P, Testa RJ, Pflum S, et al. The relationship between genderbased victimization and suicide attempts in transgender people. Prof Psychol Res Pract 2012;43:468-475.

4. Reisner SL, Biello KB, White Hughto JM, et al. Psychiatric diagnoses and comorbidities in a diverse, multicity cohort of young transgender women: baseline findings from project lifeskills. JAMA Pediatr 2016;170:481-486.

5. Ybarra ML, Mitchell KJ, Koskiw J. The relation between suicidal ideation and bullying victimization in a national sample of transgender and non-transgender adolescents. In: Youth Suicide Bullying: Challenges and Strategies for Prevention and Intervention. (Goldblum P, Espelage DL, Chu J, Bongar B; eds) New York: Oxford University Press, 2014, pp. 134-145.

6. Meyer $\mathrm{IH}$. Minority stress and mental health in gay men. J Health Soc Behav 1995;36:38-56. 
7. Lewis RJ, Derlega VJ, Griffin JL, Krowinski AC. Stressors for gay men and lesbians: life stress, gay-related stress, stigma consciousness, and depressive symptoms. J Soc Clin Psychol 2003;22:716-729.

8. Hendricks ML, Testa RJ. A conceptual framework for clinical work with transgender and gender nonconforming clients: an adaptation of the minority stress model. Prof Psychol Res Pract 2012;43:460-467.

9. Testa RJ, Habarth J, Peta J, et al. Development of the gender minority stress and resilience measure. Psychol Sex Orientat Gend Divers 2015;2:65-77.

10. Greytak EA, Kosciw JG, Diaz EM. Harsh Realities: The Experiences of Transgender Youth in Our Nation's Schools. New York: GLSEN, 2009. Available at http://eric.ed.gov/?id=ED505687 (last accessed December 5, 2017).

11. McGuire JK, Anderson CR, Toomey RB, Russell ST. School climate for transgender youth: a mixed method investigation of student experiences and school responses. J Youth Adolesc 2010;39:1175-1188.

12. Mitchell KJ, Ybarra ML, Korchmaros JD. Sexual harassment among adolescents of different sexual orientations and gender identities. Child Abuse Negl 2014;38:280-295.

13. Reisner SL, Greytak EA, Parsons JT, Ybarra ML. Gender minority social stress in adolescence: disparities in adolescent bullying and substance use by gender identity. J Sex Res 2015;52:243-256.

14. Grossman AH, D'Augelli AR. Transgender youth and life-threatening behaviors. Suicide Life Threat Behav 2007;37:527-537.

15. Meyer IH. Resilience in the study of minority stress and health of sexual and gender minorities. Psychol Sex Orientat Gend Divers 2015;2:209-213.

16. Simons L, Schrager SM, Clark LF, et al. Parental support and mental health among transgender adolescents. J Adolesc Health 2013;53:791-793.

17. Bockting WO, Miner MH, Swinburne Romine RE, et al. Stigma, mental health, and resilience in an online sample of the US transgender population. Am J Public Health 2013;103:943-951.

18. Goodenow C, Szalacha L, Westheimer K. School support groups, other school factors, and the safety of sexual minority adolescents. Psychol Sch 2006;43:573-589.

19. Heck NC, Flentje A, Cochran BN. Offsetting risks: high school gay-straight alliances and lesbian, gay, bisexual, and transgender (LGBT) youth. Sch Psychol Q 2011;26:161-174.

20. Poon C, Saewyc EM, Chen W. Enacted stigma, problem substance use, and protective factors among Asian sexual minority youth in British Columbia. Can J Commun Ment Health 2011;30:47-64.

21. Fazio AF. A concurrent validational study of the NCHS General Well-Being Schedule. Vital Health Stat 2 1977;73:1-53.

22. Patten SB. Performance of the Composite International Diagnostic Interview Short Form for major depression in community and clinical samples. Chronic Dis Can 1997;18:109-112.

23. Bonny $A E$, Britto $M T$, Klostermann BK, et al. School disconnectedness: identifying adolescents at risk. Pediatrics 2000;106:1017-1021.

24. Furlong MJ, O'Brennan LM, You S. Psychometric properties of the Add Health School Connectedness Scale for 18 sociocultural groups. Psychol Sch 2011;48:986-997.

25. Saewyc EM, Edinburgh LD. Restoring healthy developmental trajectories for sexually exploited young runaway girls: fostering protective factors and reducing risk behaviors. J Adolesc Health 2010;46:180-188.

26. Resnick MD, Bearman PS, Blum RW, et al. Protecting adolescents from harm: findings from the National Longitudinal Study on Adolescent Health. JAMA 1997;278:823-832.

27. Gjesfjeld CD, Greeno CG, Kim KH. A confirmatory factor analysis of an abbreviated social support instrument: the MOS-SSS. Res Soc Work Pract 2008;18:231-237.

28. Rubenstein $\mathrm{JL}$, Heeren T, Housman $\mathrm{D}$, et al. Suicidal behavior in "normal" adolescents: risk and protective factors. Am J Orthopsychiatry 1989;59:59-71.

29. Clark TC, Lucassen MFG, Bullen $P$, et al. The health and well-being of transgender high school students: results from the New Zealand Adolescent Health Survey (Youth'12). J Adolesc Health 2014;55:93-99.

30. St. John A, Travers R, Munro L, et al. The success of gay-straight alliances in Waterloo region, Ontario: a confluence of political and social factors. J LGBT Youth 2014;11:150-170.

31. Saewyc EM, Konishi C, Rose HA, Homma Y. School-based strategies to reduce suicidal ideation, suicide attempts, and discrimination among sexual minority and heterosexual adolescents in Western Canada. Int J Child Youth Family Stud 2014;5:89-112.

32. Veale JF, Saewyc EM, Frohard-Dourlent $H$, et al. Being Safe, Being Me: Results of the Canadian Trans Youth Health Survey. Vancouver, BC:
Stigma and Resilience Among Vulnerable Youth Centre, 2015. Available at https://saravyc.sites.olt.ubc.ca/files/2015/05/SARAVYC_Trans-YouthHealth-Report_EN_Final_Web2.pdf (last accessed December 5, 2017).

33. Strauss $P$, Cook A, Winter $S$, et al. Trans pathways: the mental health experiences and care pathways of trans young people. Summary of results. Perth, Australia: Telethon Kids Institute, 2017. Available at www .telethonkids.org.au/globalassets/media/documents/brain-behaviour/ trans-pathwayreport-web.pdf (last accessed December 5, 2017).

34. Rimes KA, Goodship N, Ussher G, et al. Non-binary and binary transgender youth: comparison of mental health, self-harm, suicidality, substance use and victimization experiences. Int J Transgenderism 2017. [Epub ahead of print]; DOI: 10.1080/15532739.2017.1370627

Cite this article as: Veale JF, Peter T, Travers R, Saewyc EM (2017) Enacted stigma, mental health, and protective factors among transgender youth in Canada, Transgender Health 2:1, 207-216, DOI: $10.1089 /$ trgh.2017.0031.

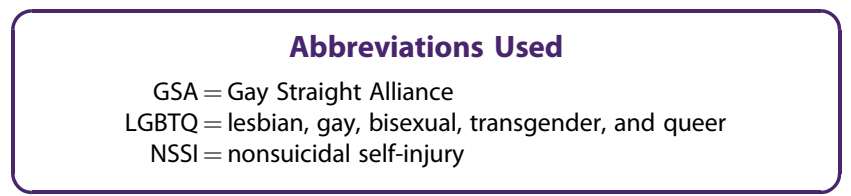

